\title{
Patient Reported Experience Measures (PREMs) in chronic heart failure
}

\author{
${ }^{1}$ E Lagha, ${ }^{2} \mathrm{~A}$ Noble, ${ }^{3} \mathrm{~A}$ Smith, ${ }^{4} \mathrm{MA}$ Denvir, ${ }^{5} \mathrm{SJ}$ Leslie \\ ${ }^{1}$ Medical student, University of Aberdeen, School of Medicine and Dentistry; ${ }^{2}$ Staff Nurse, NHS Highland, Raigmore Hospital, Inverness; \\ ${ }^{3}$ Heart Failure Specialist Nurse, NHS Highland, Raigmore; ${ }^{4}$ Consultant Cardiologist, Edinburgh Heart Centre, Royal Infirmary of Edinburgh; \\ ${ }^{5}$ Consultant Cardiologist, NHS Highland, Raigmore Hospital, Inverness and University of Stirling, Inverness
}

\begin{abstract}
Background: Patient Reported Experience Measures (PREMs) is an essential tool for assessing the quality of chronic disease management. The optimal method for delivering a PREMs survey however is unknown. This study reports two methods for assessing PREMs in patients with chronic heart failure (CHF).

Methods: A bespoke online and postal survey delivered to community-based CHF patients in Scotland.

Results: A total of 121 patients (73 postal and 48 online) completed the survey. The online cohort were younger, had less contact with a CHF nurse, were more likely to see a CHF doctor and seemed less satisfied with the quality of clinical services. The postal cohort returned fewer negative comments (20 [27.4\%] vs 28 [58.3\%]; $\mathrm{p}<0.000 \mathrm{I})$. Several recurring themes were identified.

Conclusions: There are differences in participation rates and responses between postal and online surveys; the accuracy of the feedback gathered using these methods is therefore difficult to determine. Clinicians should consider offering a range of options to enable patients to reflect and 'voice' their opinions regarding clinical services.
\end{abstract}

KEYWORDS Patient satisfaction, internet, worldwide web, heart failure

DECLARATION OF INTERESTS No conflicts of interest declared.

\author{
Correspondence to SJ Leslie, \\ Cardiac Unit, Raigmore \\ Hospital, Inverness \\ IV2 3UJ, UK
}

tel. +44 (0) 1463705462 e-mail stephen.leslie@nhs.net

\section{BACKGROUND}

The optimal management of chronic diseases such as chronic heart failure (CHF) relies on a high degree of patient concordance with lifestyle measures, medications and therapeutic interventions. Concordance is more likely if patients understand their condition and have confidence in the healthcare providers and the treatment they are receiving. The process of asking patients to report their views on a service seems itself to improve satisfaction with that service and of course patient's views and opinions can guide service improvement and redesign. ${ }^{12}$ For these reasons, assessing patient-related experiences with clinical services is crucial to good quality chronic disease management. Furthermore, patients' views are increasingly being recognised as a legitimate healthcare outcome. ${ }^{3,4}$

However, participation in patient satisfaction surveys is not uniform and is less likely in patients with poor health status. ${ }^{5-7}$ Patients tend to report more positive than negative experiences in patient surveys and reporting bias may also exist. One method for gathering feedback on patient experience is the Patient Reported Experience
Measures (PREMs) tool. The optimal technique for deploying this tool is, however, unknown and likely to vary in different clinical settings and patient groups and there are no data to compare one technique directly with another. However, as patients are increasingly turning to the internet for health information, ${ }^{8.9}$ including more elderly cardiac patients, ${ }^{10}$ using online patient satisfaction surveys offers the potential to gain a wider range of views at a low cost and may offer greater anonymity than paperbased surveys delivered by a local clinical team.

Our study aimed to measure PREMs in patients with CHF using two methods; a traditional paper-based postal survey and an online survey.

\section{METHOD}

\section{Design}

We used a questionnaire-based patient satisfaction survey and compared postal responses with a webbased online survey. 


\section{Participants}

Two cohorts of patients with heart failure were studied. A paper-based postal survey was sent to all active patients in the Highland Heart Failure Service. A similar online survey was developed using an online survey tool. It was advertised to heart failure nursing teams across Scotland and also by a web link on a national charity (Chest Heart \& Stroke Scotland [CHSS]) website.

\section{Survey design}

A bespoke survey was developed using a multi-step iterative process based on previous patient satisfaction surveys and in consultation with local patients and staff. Data collected included patient gender, age, New York Heart Failure Association (NYHA) classification, current medications (from a list), time taken to travel to hospital, patient contact with CHF nurses and specialist doctors, patient satisfaction rating and patient satisfaction with information given, on a scale of $0-10$. These were subsequently grouped into ratings of $0-3$ (poor), 4-6 (average) and 7-10 (good).

\section{Quantitative data collection and statistical analysis}

All data including open question responses from the postal forms were transcribed, while the online data were automatically collated and extracted into a database.

\section{Qualitative data collection and thematic analysis}

Free text comments were transcribed and patient or service identifiers were removed to ensure anonymity. The comments were coded and grouped on a thematic basis as generally positive or negative prior to a more detailed analysis. All responses and emergent themes were subsequently reviewed by two additional coders.

\section{Ethical approval}

The aim of this study was to employ PREMs with a view to service evaluation; ethical approval was therefore not deemed necessary.

\section{RESULTS}

A total of 121 patients (73 postal and 48 online) completed a survey.

\section{Quantitative results}

The results are shown in Table I. The two cohorts were generally well-matched, although the online cohort were younger, had less contact with a CHF nurse, but were more likely to see a CHF doctor (all $\mathrm{p}<0.0 \mathrm{I}$ ). They were
TABLE I Demographics

\begin{tabular}{|c|c|c|c|}
\hline & $\begin{array}{c}\text { Postal } \\
\text { survey } \\
\text { n (\%) }\end{array}$ & $\begin{array}{l}\text { Online } \\
\text { survey } \\
\text { n (\%) }\end{array}$ & p value \\
\hline $\begin{array}{l}\text { Number of } \\
\text { patients }\end{array}$ & 73 & 48 & NA \\
\hline Male gender & $46(63.0)$ & $29(60.4)$ & 0.773 \\
\hline $\begin{array}{l}\text { Age years } \\
\text { (mean } \pm \text { SD) }\end{array}$ & $73.0 \pm 12.2$ & $60.9 \pm 13.1$ & $<0.0001$ \\
\hline \multicolumn{4}{|l|}{ NYHA class } \\
\hline I & $9(12.3)$ & $5(10.4)$ & \\
\hline II & $26(35.6)$ & $13(27.1)$ & \\
\hline III & $27(37.0)$ & $24(50.0)$ & \\
\hline IV & II (I5.I) & $6(12.5)$ & $\begin{array}{l}0.563 \text { (for } \\
\text { group) }\end{array}$ \\
\hline \multicolumn{4}{|l|}{ Medications } \\
\hline Ace inhibitor & $50(68.5)$ & $33(68.8)$ & 0.707 \\
\hline Beta blocker & $53(72.6)$ & $37(77.1)$ & 0.581 \\
\hline Digoxin & $25(34.2)$ & $10(20.8)$ & 0.111 \\
\hline Spironolactone & $25(34.2)$ & $22(45.8)$ & 0.201 \\
\hline Eplerenone & $2(2.7)$ & $6(12.5)$ & 0.035 \\
\hline Warfarin & $25(34.2)$ & $19(39.6)$ & 0.551 \\
\hline Aspirin & $4 \mid(56.2)$ & $18(37.5)$ & 0.044 \\
\hline \multicolumn{4}{|l|}{$\begin{array}{l}\text { Travel time } \\
\text { from home to } \\
\text { hospital (mins) }\end{array}$} \\
\hline $0-30$ & $47(64.4)$ & $23(47.9)$ & \\
\hline $31-60$ & $23(3 \mid .5)$ & 18 (37.5) & \\
\hline $61-120$ & $3(4.1)$ & $7(14.6)$ & $\begin{array}{l}0.064 \text { (for } \\
\text { group) }\end{array}$ \\
\hline $\begin{array}{l}\text { Contact with } \\
\text { CHF nurse? }\end{array}$ & 71 (97.3) & $32(66.7)$ & $<0.0001$ \\
\hline $\begin{array}{l}\text { Contact with } \\
\text { CHF specialist } \\
\text { doctor? }\end{array}$ & $30(4 I . I)$ & $29(60.4)$ & 0.038 \\
\hline \multicolumn{4}{|l|}{$\begin{array}{l}\text { Patient } \\
\text { satisfaction } \\
\text { rating }(1-10)\end{array}$} \\
\hline 0-3 (poor) & $2(2.7)$ & $6(12.5)$ & \\
\hline 4-6 (average) & $8(11.0)$ & $14(29.2)$ & \\
\hline 7-10 (good) & $63(86.3)$ & $28(58.3)$ & $\begin{array}{l}0.002 \text { (for } \\
\text { group) }\end{array}$ \\
\hline $\begin{array}{l}\text { Given adequate } \\
\text { information } \\
\text { regarding CHF? }\end{array}$ & $63(86.3)$ & 35 (72.9) & 0.066 \\
\hline $\begin{array}{l}\text { Positive } \\
\text { comments }\end{array}$ & 14 & 5 & \\
\hline $\begin{array}{l}\text { Negative } \\
\text { comments }\end{array}$ & 20 & 28 & \\
\hline \multicolumn{4}{|c|}{$\begin{array}{l}\text { NYHA = New York Heart Association classification; } \\
\text { CHF= Chronic heart failure }\end{array}$} \\
\hline
\end{tabular}


less likely to be prescribed digoxin but more likely to be prescribed aldosterone antagonists. The online cohort seemed to be less satisfied with clinical services.

\section{Qualitative results}

Compared to the online cohort, the postal cohort returned fewer negative comments (20 [27.4\%] vs 28 [58.3\%]; $\mathrm{p}<0.000 \mathrm{I})$ and there was a trend towards more positive comments (14 [19.1\%] vs 5 [6.8\%]; $p=0.195)$.

There were many positive comments:

'The [heart failure nurse] service is first class' (postal); 'The heart failure nurse is a great help' (online); 'Mum has been very well cared for, her heart nurse has been excellent' (postal); 'I am aware of my limitations and can therefore manage quite well' (postal).

However, many patients shared similar concerns. One theme involved local access to services and transport difficulties:

'When attending [local hospital] transport is a problem' (postal); 'Would like heart failure group locally'(online); 'Would like to attend heart failure meetings. One held in [town] at times would be accessible for me' (postal).

There were also recurring themes about clinical staff and services:

'Insufficient information - seeing a registrar at [local hospital] clinic who knew little or nothing about my situation and who was not prepared to answer any of my questions, does not instil confidence and tends to negate excellence of previous appointments'(postal); 'I find doctors/specialists do not take the time to explain and do not follow up with appointments and aftercare' (online);'More access to regular appointments with a heart failure nurse' (online); 'Apparent lack of concern by health professionals, of condition, e.g. have to ask for blood tests, BP monitoring etc. However, seeing the same doctor in cardiology would still be helpful' (online).

Psychosocial issues were cited by others:

'Concerned that this could happen again and I could land back in hospital' (postal); 'Not really any concerns only about the pacemaker and defibrillator. Terrified of that going off again. That's all really' (postal); 'Depression. Would like to alleviate fear of uncertainty'(online); 'Apart from wondering how it will all end' (online); 'Worrying about the condition does not help' (online).

Some patients felt that general information was lacking: 'Would like general public having more knowledge of how your life and your immediate family are affected by the condition' (postal); 'Is this how I am going to be for the rest of my life?' (postal); 'Not given prognosis and reluctant to ask, but have been assured that my condition has shown some improvement' (postal); 'More frank information' (online); 'Would like to find a way to get rid of fluid' (online); 'Found out all information on my own. I no longer live an active, normal, working life' (online).

Physical concerns were also mentioned:

'At age 83 I have learnt to live within the parameters my heart condition allows, after valve surgery three years ago. Mostly what concerns me is the lack of stamina for any physical activity e.g. walking, mild exercise - breathlessness etc. Weak legs' (postal); 'Shortness of breath when walking in the hills. I have to stop more often than I used to' (postal).

\section{DISCUSSION}

Our study has demonstrated that there may be differences between postal and online survey results in assessing PREMs, both in terms of the types of patients who responded and their opinions of clinical services.

\section{Assessing PREMs}

Patient Reported Experience Measures can be assessed in a variety of ways, both qualitatively and quantitatively. ${ }^{10}$ Qualitative research is usually conducted using face-toface interviews, paper-based, telephone or online surveys. This is believed to be the most successful way of accurately obtaining information related to patient experience and allow a greater depth and flexibility of responses compared with quantitative techniques." However, these methods can lack credibility as they may be susceptible to interpretation, are often difficult to organise and are more costly to deliver. Quantitative satisfaction scales and conceptual frameworks are therefore often more commonly used. ${ }^{12,13}$

\section{Patient opinions of heart failure service}

There is increasing recognition of the value of patient satisfaction surveys, although their reliability and utility have not yet been fully established. Our results suggest that the online cohort were less satisfied with the service when compared to the postal survey cohort. This may reflect an actual difference in services when comparing our area with the rest of Scotland but this is unlikely, as the majority of postal surveys returned very positive results. It is more likely that either the online survey attracted a different cohort of patients or patients are more willing to be critical when completing an online survey. Internet-based patient surveys may offer greater real (and patient perceived) anonymity and therefore less reporting bias compared to paper-based 
postal surveys; these are often administered by the clinicians who deliver the clinical service, arguably compromising the anonymity of each patient's response and reducing the likelihood of a patient expressing his/ her true feelings towards the service for fear of being personally identified as dissatisfied. Patients who feel grateful to the NHS as a whole may feel obliged to report more positive feedback on their personal experiences. We have previously reported high satisfaction with a CHF volunteer befriending service using a paper-based approach and found that there was remarkable homogeneity of feedback and very few negative responses. ${ }^{14}$

At this early stage in the development of PREMs, online surveys may give clinicians and service providers more information. The finding that the online cohort were less satisfied is in keeping with the hypothesis that online collection of data may be more reliable and closer to the patient's true experience given the acknowledged falsely positive responses from paper-based postal surveys. Alternatively, it is also possible that online submission provides a more easily accessible forum for less satisfied and more outspoken patients. For example, an annoyed patient wishing to complain may be more likely to opt in to an online patient satisfaction survey than a satisfied patient.

Any group response will have some degree of heterogeneity as, for a variety of reasons, patients in the same service will have different illness perceptions and different experiences. Nevertheless, it is tempting to speculate that an online approach will result in a more honest, if critical response. The aim of a survey is to establish the patient's perceived experience; the 'truth' or reality of a situation is arguably irrelevant. There is also debate around the appropriate response to the critical observations of a few patients, even with more survey data available. New systems and processes might need to be developed to encourage responsiveness within clinical services based on the results of PREMs. The mechanisms and resources required to do this remain unclear.

Health professionals themselves seem to predict greater levels of dissatisfaction in their patients than surveys report. ${ }^{15}$ It has been well documented in the literature that patient satisfaction surveys routinely return very positive results, with the majority of patients reporting high degrees of satisfaction and a reluctance to criticise their healthcare service; ${ }^{16}$ although it is possible that poorly performing clinical services are less likely to publish poor results of patient surveys. This issue has called into question the reliability of patient satisfaction surveys in general. It is likely that the validity and utility of patient-reported experiences will be better assessed using large sample sizes acquired over medium to long time periods with careful assessment of the temporal trends in data.
Assessing the validity of the patient comments was outside the scope of this current study, but it is likely that the negative comments are an underestimation of the number of patients who have had a negative experience. Nevertheless, there were many positive comments and overall satisfaction with the clinical service was high.

\section{Response rate}

There was a much greater response rate to the postal survey. The exact response rate for the online survey was difficult to determine as the denominator was not known, but it was very low, and much lower than the authors anticipated. This was despite advertising through the Scottish Heart Failure Nurse Network as well as placing an advert in a prominent position on the website of a major national heart charity.

\section{Cost and access}

Online systems for patient surveys have the potential to reach a wider audience. Automatic collation of results and reporting may make this method of patient survey much more appealing in the future due to lower costs and potentially greater access for participants.

\section{Limitations}

The two cohorts of patients had experienced clinical services in different geographical areas. All respondents were in Scotland, where nurse-led community-based heart failure services are widespread; we therefore believe that the quality of clinical services does not vary significantly enough to make a difference in the responses. Furthermore, the online patient survey sample size was small, despite being featured on the CHSS website and being advertised through clinical networks. If online surveys are to be used effectively, then additional and innovative ways of engaging with patients will be required. We accept that our survey may have had weaknesses in assessing true patient satisfaction levels. Determining which survey method provided more accurate results is difficult. This is an area where further research to directly compare approaches under more controlled study conditions might be useful.

\section{CONCLUSIONS}

Postal and online surveys have advantages and disadvantages. The true accuracy of the results gathered through each approach is difficult to determine. Ultimately, our aim should be to gather as much data from as wide a cross section of the patient population as we can in order to enhance patient experience of clinical services by redesigning and developing our services based on accurate and representative feedback. 


\section{REFERENCES}

I Sen S, Fawson P, Cherrington $G$ et al. Patient satisfaction measurement in the disease management industry. Dis Manag 2005; 8:288-300. http://dx.doi.org/I0.1089/dis.2005.8.288

2 Stroupe KT, Hynes DM, Giobbie-Hurder A et al. Patient satisfaction and use of Veterans Affairs versus non-Veterans Affairs healthcare services by veterans. Med Care 2005; 43:453-60. http://dx.doi. org/I0.1097/0I.mlr.0000I60377.82I64.d3

3 Dunderdale K, Thompson DR, Miles JN et al. Quality-of-life measurement in chronic heart failure: do we take account of the patient perspective? Eur J Heart Fail 2005; 7:572-82. http://dx.doi. org/I0.I0I6/j.ejheart.2004.06.006

4 Dunderdale K, Thompson DR, Beer SF et al. Development and validation of a patient-centered health-related quality-of-life measure: the Chronic Heart Failure Assessment Tool. J Cardiovasc Nurs 2008; 23:364-70.

5 Etter JF, Perneger T. Analysis of non-response bias in a mailed health survey. J Clin Epidemiol 1997; 50:1/23-8. http://dx.doi. org/10.1016/S0895-4356(97)00166-2

6 Lasek RJ, Barkley W, Harper DL et al. An evaluation of nonresponse bias on patient satisfaction surveys. Med Care 1997; 35:646-52. http://dx.doi.org/I0.1097/00005650-199706000-00009

7 Lliffe S, Wilcock J, Manthorpe J et al. Can clinicians benefit from patient satisfaction surveys? Evaluating the NSF for older people, 2005-2006. J $R$ Soc Med 2008; 101:598-604. http://dx.doi. org/I0.1258/jrsm.2008.080103

8 Ayantunde AA,Welch NT, Parsons SL.A survey of patient satisfaction and use of the internet for health information. Int J Clin Pract 2007; 61:458-62. http://dx.doi.org/I0.1 I II/j.1742-124I.2006.0I094.x

9 Anderson JG. Consumers of e-health: patterns of use and barriers. Soc Sci Comput Rev 2004; 22:242-8. http://dx.doi. org/I0.II77/089443930326267I
10 Gandiya T, Dua A, King G et al. Self-reported 'communication technology' usage in patients attending a cardiology outpatient clinic in a remote regional hospital. Telemed J E Health 2012; 18:2 I9-24. http://dx.doi.org/l0.1089/tmj.20II.0III

II Sitzia J, Wood N. Patient satisfaction: a review of issues and concepts. Soc Sci Med 1997; 45: 1829-43. http://dx.doi.org//0.1016/ S0277-9536(97)00I28-7

12 Ford RC, Bach SA, Fottler MD. Methods of measuring patient satisfaction in health care organizations. Health Care Manage Rev 1997; 22:74-89.

I 3 Wiklund I, Lindvall K, Swedberg K et al. Self-assessment of quality of life in severe heart failure: an instrument for clinical use. Scand JPsychol I 987;28:220-5.http://dx.doi.org/ I0. I I I I/j. I467-9450.I987. tb00758.x

I4 Peardon L, Yellowlees D, Pratt $R$ et al. The use of innovative methods designed to relieve social isolation in patients with chronic heart failure; volunteer befriending, forums and a newsletter. Eur J Cardiovasc Nurs 2010; 9:181-7. http://dx.doi. org/I0.1016/j.ejcnurse.2009.12.001

I5 Rashid A, Forman W, Jagger C et al. Consultations in general practice: a comparison of patients' and doctors' satisfaction. BMJ 1990; 299:1015-6. http://dx.doi.org/10.1 136/bmj.299.6706.1015

16 Fitzpatrick R, Bowling A, Gibbons $E$ et al. A structured review of patientreported measures in relation to 52 selected chronic conditions, perceptions of quality of care, and carer impact [Internet]. Oxford: National Centre for Health Outcomes Development; 2006 [cited 2012 Oct 4] Available from: http://phi.uhce.ox.ac.uk/pdf/ChronicConditions/DH_ REVIEWS_NOVEMBER_2007.pdf

\section{INVITATION TO SUBMIT PAPERS}

We would like to extend an invitation to all readers of The Journal of the Royal College of Physicians of Edinburgh to contribute original material, especially to the clinical section. The JRCPE is a peer-reviewed journal with a circulation of 8,000 . It is also available open access online. Its aim is to publish a range of clinical, educational and historical material of cross-specialty interest to the College's international membership.

The JRCPE is currently indexed in Medline, Embase, Google Scholar and the Directory of Open Access Journals. The editorial team is keen to continue to improve both the quality of content and its relevance to clinical practice for Fellows and Members. All papers are subject to peer review and our turnaround time for a decision averages only eight weeks.

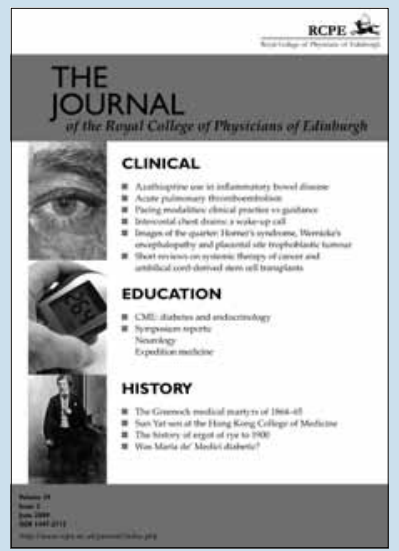

We would be pleased to consider submissions based on original clinical research, including pilot studies. The JRCPE is a particularly good forum for research performed by junior doctors under consultant supervision. We would also consider clinical audits where the 'loop has been closed' and a demonstrable clinical benefit has resulted.

For further information about submissions, please visit: http://www.rcpe.ac.uk/journal/contributers.php or e-mail editorial@rcpe.ac.uk.Thank you for your interest in the College's journal.

The editorial team,

The Journal of the Royal College of Physicians of Edinburgh 